Revista Complutense de Historia de América

ISSN: 1132-8312

http://dx.doi.org/10.5209/RCHA.61083

\title{
No hay historia global sin el Pacífico y América: el quimón en Nueva España y la circulación de tejidos de algodón pintado (siglos XVI-XIX) ${ }^{1}$
}

\author{
Andreia Martins Torres ${ }^{2}$
}

Recibido: 11 de agosto de 2016 / Aceptado: 13 de febrero de 2017

Resumen. Este trabajo pretende contribuir al debate sobre el impacto de los algodones pintados de India, en el exterior, a partir del siglo XVI. A pesar del creciente interés por el tema, no se ha considerado el contexto americano y, sobre todo, el comercio por el Pacífico. Eso repercute en una visión circunscrita de su circulación, ignorando el papel central de la Nueva España como eje de conexión entre Asia y Europa dentro del Imperio Español. Es eso lo que se tratará de combatir a partir del estudio de un tipo de algodón pintado, llamado Quimón, que disfrutó de amplia difusión en el virreinato. Se utilizarán las fuentes escritas y pictóricas para percibir el origen de esos materiales, la forma en que penetraron en el gusto de la población, hasta el punto de motivar interpretaciones locales.

Palabras clave: Textiles de algodón pintado; historia global; Pacífico; Nueva España; Japón; India; siglos XVI-XIX.

\section{[en] There is no Global History without the Pacific and America: The Quimón in New Spain and the Circulation of Print Cotton (16th-19th century)}

\begin{abstract}
This work aims to contribute to the study of the impact that painted cotton fabrics from India had on the outside world, beginning in the Sixteenth Century. Despite growing interest in this subject, previous studies have not taken into consideration the American context and Pacific trade routes. The result is a circumscribed view of the circulation of these Indian fabrics that ignores New Spain's central role as a hub connecting Asia and Europe within the Spanish Empire. This article attempts to resolve this through the study of the Quimón, a type of printed cotton which circulated widely throughout the Viceroyalty. Written and pictorial sources have been utilized to discern the origin of these materials and how they became fashionable, to the point of motivating local interpretations
\end{abstract}

Keywords: Printed Cotton Textiles; Global History; Pacific; New Spain; Japan; India; 16-19th Centuries.

Sumario. 1. Introducción. 2. Los quimones, ¿qué eran? 3. Los quimones de Nueva España: de las importaciones asiáticas a la introducción de "imitaciones" europeas y su producción en América. 4. Las aplicaciones del quimón. 5. Conclusiones. 6. Referencias bibliográficas.

Cómo citar: Torres, A. M. (2018) No hay historia global sin el Pacífico y América: el quimón en Nueva España y la circulación de tejidos de algodón pintado (siglos XVI-XIX), en Revista Complutense de Historia de América 44, 143-165.

\footnotetext{
1 Me gustaría agradecer a la editora Dra. Beatriz Rubio por la revisión de estilo que hizo sobre este texto que escribí originalmente en castellano y no es mi idioma materno.

2 CHAM (Centro de Humanidades - NOVA FCSH-UA) y NEAP (Universidade Federal de Goiás)

E-mail: andreiatorres@fcsh.unl.pt
} 


\section{Introducción}

En los últimos años se realizaron varios trabajos sobre los algodones pintados de India durante la época moderna. Una de las grandes referencias es Georgio Riello, que publicó una extensa bibliografía analizando el tema desde una perspectiva de la historia global ${ }^{3}$. El investigador se centró en la idea de circulación para defender que dichos textiles fueron la primera manufactura que tuvo verdaderamente un carácter transcontinental. Eso motivó la reestructuración mundial del comercio pero también del consumo y de las técnicas de producción. En su opinión, tales fenómenos culminarían en la revolución industrial europea, en la medida en que ésta resultó del deseo de obtener tales géneros a gran escala. El objetivo era crear una alternativa a las importaciones asiáticas para el consumo interno y la exportación hacia regiones consideradas marginales. Eso lo sostienen también autores como John Styles o Jan de Vrie, entre otros ${ }^{4}$.

Estas reflexiones resultan sumamente interesantes y ayudan a entender la complejidad del tema. Riello tuvo el gran mérito de repensar las particularidades europeas ampliamente trabajadas, por ejemplo, por las autoras Berverly Lemire o Maxine Berg, y conectar esas historias con las de otras regiones ${ }^{5}$. Al hacerlo, no solo promovió un desplazamiento del foco principal de análisis, sino que trató de considerar las dinámicas propias de otros espacios.

En lo que concierne al ámbito asiático, se valoraron las circunstancias en que se produjeron ahí esos textiles para relacionarlas con las redes de comercio inter-asiático y sus conexiones con los negocios de las grandes compañías europeas. Sobre esta materia han publicado, por ejemplo, Om Prakash, Sanjay Subrahmanyan, Lakshmi Subramanian, Prasannan Parthasarathi y George Bryan de Souza ${ }^{6}$. Asimismo hay áreas que se han mantenido relativamente marginalizadas a estos trabajos, especialmente Japón. Autores como Osamu Saito sostienen que las políticas del shogunato provocaron su aislamiento, sin capacidad de atraer los beneficios del comercio oceánico $^{7}$. No obstante, tal idea es incompatible con las inferencias hechas por Ryuto Shimada y Kayoko Fujita sobre el enorme impacto de los tejidos de la India en su comercio con el exterior, en la conformación del gusto y en las interpretaciones locales que originaron ${ }^{8}$.

Las deducciones hechas a partir del tráfico de algodones pintados en esas redes ampliaron el debate a otras áreas de influencia, especialmente hacia África. Las contribuciones hechas por Pedro Machado sobre Mozambique, de Kazuo Kobayashi en relación al valle del río Senegal, o de Joseph Inikori demuestran que los tipos de demanda africana condicionaron la producción asiática y europea para adaptarse a su público consumidor. A partir de esta oferta de tejidos, muchos de la India, se adquirió el marfil que retornaba de nuevo a esa región y también los esclavos negros que

\footnotetext{
Riello, 2008, 2010a, 2010b, 2014 y 2016; Riello - Parthasarathi, 2009 y 2012; Riello - Tirthankar, 2009. Styles, 2009, 2011 y 2016; De Vrie, 2008.

Berg, 2004, 2005 y 2009; Berg - Gottmann - Hodacs - Nierstrasz, 2015; Lemire, 1991, 2003a, 2003b, 2009, $2011,2014 a$ y $2014 b$

6 Prakash, 1985 y 2009. Subrahmanyam, 1990 y 2009; Parthasarathi, 2001 y 2009; Riello - Parthasarathi, 2012; Bryan de Souza, 2004 y 2009.

Saito, 2015.

$8 \quad$ Fujita, 2009: 194-201; Shimada, 2006.
} 
se enviaban a las grandes plantaciones americanas ${ }^{9}$. Era en estos lugares donde se cultivaba el algodón que luego se empleaba en las fábricas del Viejo Mundo durante el siglo XVIII. Algunas de esas manufacturas acababan nuevamente en el mercado africano, alimentando una espiral que unía permanentemente estos tres continentes a través de la mano de obra, de la producción de materia prima y del producto final, hasta el consumidor ${ }^{10}$.

La inclusión de América al estudio del tema surge así desde el ámbito del comercio triangular que tuvo lugar a partir de los años de 1790, cuando el Atlántico se vuelve una vía importante de circulación de textiles de algodón. Eso tuvo el efecto pernicioso de sobredimensionar el papel de los agentes europeos, ignorando otras vías de acceso a los algodones pintados de Asia o las dinámicas internas de producción.

En lo que concierne específicamente al comercio, cabe referir las frecuentes conexiones entre la India y Brasil a través de Mozambique. Aunque muchas veces eso ocurriera de manera ilegal y no se conozca el volumen de esos negocios, sería importante ponderar que, además de esclavos, circularon también textiles ${ }^{11}$. El historiador Luís Antunes estudió precisamente las relaciones de los mercaderes brasileños en la isla y observó que, para reducir las pérdidas ocurridas en los viajes transatlánticos e incrementar las ganancias con la trata de esclavos, ellos complementaban la carga con textiles de la India. Así los colocaban en el mercado americano a precios más bajos que los que llegaban por vía de la Carreira da Índia ${ }^{12}$. Cabría mencionar aún los designados "panos da costa" que se trataban de importaciones africanas con destino al consumo de la población negra, cuya demanda se vinculaba a las tendencias particulares de las regiones originarias de los esclavos brasileños ${ }^{13}$.

Pero quizás lo más perentorio para un análisis verdaderamente global sea la inclusión del Pacífico. En ese ámbito editaron un libro, en 2013, David Armitage y Alison Bashford, reivindicando el papel del Pacífico en la historia global y haciendo un estado de la cuestión en su capítulo introductorio ${ }^{14}$. Lo mismo demandaron los investigadores Carlos Martínez Shaw y Marina Alfonso Mola en un artículo conjunto sobre el papel central de Filipinas en los procesos de globalización moderna ${ }^{15}$. En esta ocasión se centraron fundamentalmente en la circulación de la plata americana, pero los avances que en los últimos años se hicieron sobre el tráfico entre Manila y Acapulco, así en España como en México, revelan el enorme peso de los textiles en esos tratos ${ }^{16}$. El Galeón fue durante varios siglos el mecanismo fundamental para garantizar una conexión entre Asia y América, pero también con Europa. Si bien durante los primeros años se hicieron algunos viajes a Perú, Nueva España fue durante mucho tiempo el principal centro redistribuidor de mercancías asiáticas. Desde ahí se distribuían hacia los virreinatos vecinos, aun cuando ese comercio estaba prohibido, y se embarcaban en los navíos de la flota hacia Europa. La progresiva liberalización comercial a partir de finales del XVIII y la creación de otras compañías

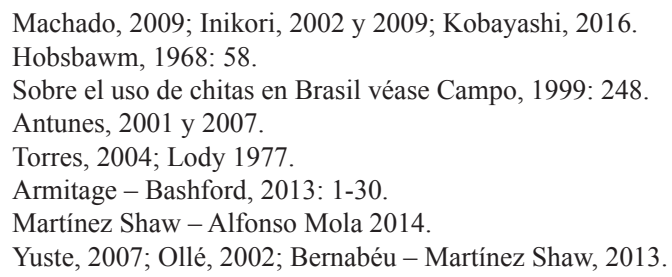


comerciales, como la Real Compañía de Filipinas (1785), amplió las posibilidades comerciales pero el galeón fue una de las principales vías de circulación de textiles asiáticos hacia "occidente", hasta $1815^{17}$.

Igualmente son aún muy pocos los trabajos centrados específicamente en este tipo de productos. Paulina Machuca hizo varias reflexiones acerca de los diferentes textiles asiáticos identificados en los inventarios de Colima sin adentrarse mucho en el tema ${ }^{18}$. Virginia Armella de Aspe escribió también un capítulo en una obra colectiva sobre la influencia de Asia en la indumentaria novohispana. En esa ocasión se basó esencialmente en los relatos de época y los registros de algunos navíos, llegando incluso a referirse a los algodones pintados ${ }^{19}$. Existen otros trabajos más centrados en determinados tipos de textiles, como el último libro publicado por Mariano Bonialian sobre la importancia de la seda en el comercio entre América y Asia ${ }^{20}$. También es interesante el capítulo recientemente publicado por Andrés del Castillo Sánchez acerca de los paliacates ${ }^{21}$. El autor trata de desmontar su vinculación con las palabras náhuatl pal y yacatl para destacar su origen etimológico en la antigua población de Paliacate (actual Pazhaverkadu), en la India ${ }^{22}$. Para esto se basa en el estudio del comercio de textiles en el puerto de Paliacate desde la antigüedad y analiza el peso de los textiles del Coromandel (India) en las relaciones con Manila. De esa manera contradice lo que ya había sostenido anteriormente Virginia Armella de Aspe que los asociaba con el puerto de Calicut/Palicut ${ }^{23}$.

Por lo general, la omisión de estas conexiones lleva a Riello a considerar América como una región periférica en la circulación de algodones pintados, definiéndola como un mercado a donde se destinaban las reexportaciones de ejemplares asiáticos desde Europa o las imitaciones que se hacían en sus talleres. Así interpreta los resultados de la investigación de Abby Sue Fisher sobre los rasgos de la indumentaria novohispana en los cuadros de $\operatorname{castas}^{24}$. No obstante, tales inferencias resultan de generalizaciones hechas a partir del estudio de los casos centroeuropeos y sus compañías comerciales. Como mucho se incorpora la realidad portuguesa, que también estuvo más enfocada en el área atlántica. Pero si se tienen en cuenta las particularidades del Imperio Español y el papel central de la Nueva España en la circulación de mercancías asiáticas dentro del territorio dominado por la Corona, rápidamente se perciben las incompatibilidades de esos postulados. Durante mucho tiempo el virreinato fue la principal vía de acceso a esos géneros para los peninsulares y, como demuestra Carmen Yuste, sus élites controlaron el negocio a través de la institución del situado de Filipinas y del Consulado de Comerciantes ${ }^{25}$. Fue solo a finales del siglo XVIII cuando se creó una alternativa interna a la intermediación novohispana, con la fundación de la Real Compañía de Filipinas y la inauguración de una conexión directa entre la península y Manila, por la Ruta del Cabo.

Sobre el importante papel del Galeón de Manila en la distribución de quimones y quimonos véase Martins Torres, 2013.

18 Machuca, 2012.

19 Armella de Aspe, 1992.

20 Bonialian, 2014.

21 Especie de pañoleta. Consiste en un lienzo cuadrado doblado de manera que forma un triángulo y se usa atado al cuello.

22 Del Castillo, 2016.

23 Armella de Aspe, 1992: 54.

24 Fisher, 1992.

25 Yuste, 2007. 
Otro factor a tener en cuenta es el sector textil novohispano y sus características. Muchas de las sociedades prehispánicas desarrollaron una relevante producción de tejidos de algodón que, en Mesoamérica, se usaron también como moneda. Estas tenían una medida concreta y podían ser totalmente blancas o estar decoradas con bordados y pinturas. Estos diseños se hacían con pintaderas, una especie de sello de barro con el que se imprimían sucesivamente los motivos en las telas. La Matrícula de Tributos constituye un importante elemento para evaluar la importancia de las mantas de algodón en el sistema tributario del Imperio Azteca ${ }^{26}$. Esa realidad se mantuvo durante los primeros momentos de la colonización española y, con el tiempo, los grandes telares novohispanos estuvieron controlados por peninsulares y criollos, como lo demuestran los estudios clásicos de Manuel Miño Grijalba ${ }^{27}$. Esa estructura posibilitó que, a finales del siglo XVIII, surgiera una producción fabril más compleja para ofrecer una alternativa a los textiles asiáticos y europeos. El ejemplo más trabajado hasta ahora es la fábrica de indianillas de Francisco Iglesias, creada en 1790 y con actividad durante los primeros años del siglo posterior ${ }^{28}$.

El crecimiento del sector de textiles pintados, a finales del siglo XVIII, se debió a varios factores. En primer lugar, las guerras en Europa habían motivado cierto distanciamiento comercial con la metrópolis debido a los peligros de ataque a la flota. La menor injerencia peninsular en el comercio de importación americano dejó espacio al desarrollo local de las artes industriales, especialmente del ramo textil que representó siempre un segmento importante en las mercaderías conducidas desde Europa $^{29}$.

En segundo lugar, este período coincidió con un incremento significativo de las plantaciones de algodón que, tal como señala Jesús Hernández, creó las bases para el fomento del sector ${ }^{30}$. Además de las mantas indígenas, esos talleres empleaban también ejemplares importados de Asia sobre los cuales se pintaban/estampaban interpretaciones de los motivos florales que aparecían en los famosos tejidos de la India. Para el efecto, contaron con la disponibilidad de plantas tintóreas americanas como la grana y el añil con los que seguramente se hicieron los "ocho [quimones] carmines mexicanos" o los cinco "dichos azules mexicanos" que tenía Don Simón de los Villares en su tienda de Villa de Lagos, en $1785^{31}$. Por eso no se puede determinar si los cinco "quimonos azules de Selaya, ordinarios" que constan del balance de la tienda de Juan López Cancelada, estaban efectivamente confeccionados con mantas autóctonas o sobre textiles importados ${ }^{32}$. Lo mismo se podría decir en relación a los

\footnotetext{
Miño Grijalva, 1990: 244-245; 1993: 188-189; Berdan - Durand-Forest, 1980.

Véanse también: Morales Moreno, 2005; Phipps, 2014; Salvucci, 1987; Thomson, 2002.

Las indianillas eran tejidos pintados o estampados que tenían por materia prima mantas de algodón y también lienzos de seda, lino y cáñamo. Miño Grijalva, 1984: 135-138; Arias Estrada, 2010; 2013: 288-382.

29 Hernández Jaimes, 2003.

30 Eso sucedió en la fábrica de indianillas de Francisco Iglesias que, en el año de 1801, hacía estampados sobre algodón criollo y de China. Miño Grijalva, 1984: 136.

31 Doña Mariana Fernanda Fernandez Munilla viuda de Don Simon de los Villares, vecino y del comercio que fue de esta ciudad contra Bernardo Marcelino de Villar, del comercio de Villa de Lagos, sobre pesos. Lagos, 19-XII1785. Archivo General de la Nación [México] (en adelante AGNM), Consulado, vol. 40, exp. 4, f. 22r.

32 Autos que se siguen por parte de Domingo Antonio Salgueiro, comerciante de Veracruz, en contra de Juan Lopez Cancelada, por el pago de mercancía procedente de Cadiz, que se entregó a comisión. México, 7-XI-1805. AGN, Consulado, vol. 161, exp. 14, f. 272r.
} 
"quimones azules criollos" y los "Quimones de Guadalajara" que aparecen entre los textiles introducidos en Durango, ya en $1805^{33}$.

La gran diferencia con la India fue esencialmente la incapacidad de sacar partido de esos recursos en el mercado de exportación e intervenir en la moda de otras regiones. Aunque a mediados del siglo XVI la Nueva España exportara algodones a Europa, como reconoce Giorgio Riello, la región no logró expandir el comercio de textiles de algodón pintado indígenas hacia el exterior del continente. La larga tradición en el territorio sugiere que se hicieron piezas de gran calidad, pero los únicos ejemplares enviados a la península serían muestras de las curiosidades de esas tierras $^{34}$. Para eso pudo haber influido una visión occidental que confería mayor notoriedad a los productos orientales y despreciaba los americanos, con excepción quizás de la famosa cerámica modelada de Guadalajara que se exportó en grandes cantidades, sobre todo durante el siglo XVIII.

Todo lo anterior demuestra la necesidad de profundizar el conocimiento sobre los algodones pintados en Nueva España y de insertar las dinámicas relacionadas con la producción, comercio y el gusto una perspectiva global, capaz de relacionar el fenómeno local con el panorama regional americano y mundial. Este trabajo se centrará únicamente en un tipo particular, designado quimón, para destacar el componente japonés y de la India en la moda virreinal.

\section{Los quimones, ¿qué eran?}

La palabra quimón (pl. quimones), igual que quimono (pl. quimonos), se formó a partir del vocablo japonés kimono, y aparecen en la documentación novohispana a partir del siglo XVI. Durante mucho tiempo ambos términos señalados sirvieron para referirse indistintamente a un tejido de algodón muy fino, pintado y estampado, del tamaño de ocho varas, y a cierta bata confeccionada con una pieza con esas dimensiones incluso de otros textiles que no fueran ese algodón ${ }^{35}$. Aparentemente solo en el siglo XX se diferenció ortográficamente la tela de quimón del traje de quimono, dificultando la interpretación de las fuentes escritas de períodos anteriores cuando no se menciona el contexto de uso $^{36}$. Para evitar confundirlos, se denominará quimón al tejido, quimono al traje, y a los originales kimono.

Para entender la historia de estos tejidos y su asociación con un tipo de bata japonesa en el mundo hispano habrá que aclarar algunas circunstancias relacionada con la moda nipona. El kimono es una prenda de formas anchas y largas que evolucionó del kosode para adquirir un significado especial, vinculado a cuestiones políticas y

33 Del Río, 2009: 115 (fuente citada: Facturas registradas en la Aduana de Durango en 1805. Durango, 1805. Archivo Histórico del Estado de Durango, Serie Ingresos, caja 16, exp. 127).

34 Para el efecto cita el trabajo de Sanz, 1979.

35 Real Academia Española (en adelante RAE), 1803: 708. Aparentemente el quimón estaba hecho con hilos de algodón pero, en ocasiones, se mezclaron otras fibras naturales, particularmente de coco, como los "quimones azules mexicanos de coco" que comercializaron los poderosos mercaderes José Luis Fagoaga y Esteban Gach a finales del siglo XVIII (Libro de cajas en donde se consignan las memorias de generos a Sonora, a Esteban Gach, a cuenta de Jose Luis Fagoaga y Manuel Ximenez del Arenal. México, 7-II-1756. AGNM, Consulado, vol. 240, exp. 2, f. 258). Cabe referir que por "pieza" se entiende una porción de tejido confeccionado de una vez.

36 Alemany y Bolufer, 1917: 1402. 
culturales internas ${ }^{37}$. Las ropas más refinadas se hacían con los textiles importados de Persia e India, que inicialmente llegaban en pequeñas cantidades y conferían prestigio a quienes las vestían. A mediados del siglo XVI, las nuevas configuraciones políticas y comerciales en Asia colocaron a los portugueses como uno de los principales proveedores de los algodones de la India en Japón. Más tarde, el comercio estuvo dominado por la holandesa Vereenigde Oost-Indische Compagnie (VOC), que compitió directamente con los chinos en ese nicho de mercado, duplicando su negocio ${ }^{38}$. Aunque alrededor de 1630 se empezaran a producir imitaciones en Holanda para hacer kimonos y otras aplicaciones, los talleres locales no consiguieron los colores vivos que tenían los originales. Las innovaciones técnicas y decorativas introducidas por los artesanos japoneses no desplazaron a los ejemplares extranjeros que siguieron disfrutando de mejor reputación hasta finales del siglo XVIII ${ }^{39}$. A esos tejidos de la India, los japoneses llamaban sarasas, posiblemente en alusión a Surat, una de las ciudades donde se producían ${ }^{40}$. Al igual que en Europa y América, la penetración de estas piezas influyó en la circulación, en el gusto y también en la técnica ${ }^{41}$. Por eso, la palabra sarasa se complementó con prefijos y sufijos para designar a las imitaciones y asociarlas a su local de producción. A esa transformación cultural Kayoko Fujita designó como "indianización de Japón” y es este componente de la India que deberá tenerse en cuenta a la hora de descifrar el impacto de los quimones en el exterior y su contribución a la "japonización novohispana"42.

Si bien en Japón no existía la tela de quimón como tal, sí se usó preferentemente un tipo de tejido en la confección de kimonos. Se trataba de un algodón pintado de India, o al estilo de esa región, que tenía exactamente las mismas características del quimón, o sea, estaban hechos con la misma fibra y decorados igual. Además, el tamaño de la pieza de quimón era equivalente a la del kimono, lo que condujo a una superposición de conceptos, confundiendo el vestido con su material que, en última instancia, era lo que los japoneses designaban como sarasa. Eso justifica también que la separación clara entre ambos conceptos ocurriera tan tardíamente. Pero, sobre todo, evidencia una fuerte asociación de ciertos textiles de la India con Japón en el imaginario de los castellanoparlantes ya que su inclusión al idioma ocurrió antes mismo que empezaran a hacerse las primeras imitaciones niponas.

Según se pudo averiguar, en la Nueva España el quimón se asoció normalmente con otros tejidos de algodón, como si se trataran de sinónimos. En la documentación se detectó eso relativamente a las zarazas, a las chitas y elefantes, que aparentemente se diferenciaban unos de otros por el tamaño de la pieza ${ }^{43}$. Sin embargo, el criterio

37 El kosode es otro traje japonés, distinto al kimono. Sobre la importancia del kimono en la cultura japonesa y su asociación con la vida urbana: Tanimoto, 2009; Dalby, 2001; Matsunosuke, 1997; Gluckman - Takeda, 1992.

38 Gaastra, 1996: 93-94

39 Kamada, 2012: 1-11.

40 Además de Madrás y Bengala (Fujita, 2009: 194-201).

41 Aunque Osamu Saito (2015: 399-419) sostenga que Japón no alcanzó los beneficios del comercio oceánico, los trabajos de Ryuko Shimada (2006) y Kayoko Fujita (2009: 194-201) demuestran el enorme impacto de los tejidos indianos en su comercio con el exterior, en la conformación del gusto y en las interpretaciones locales que originaron.

42 Fujita, 2009: 194-201.

43 Estas coincidencias aparecen en inventario de los géneros que existían, en 1802, en el caxon y almacenes de la casa $\mathrm{n}^{\circ} 4$ en la primera calle de la Monterrilla (Ciudad de México) en el que constan " 6 chitas ó quimones de china”. Lo mismo sucede en el inventario y demostración general de géneros correspondientes a la compañía de D. José Bernardo Baz con Domingo Beregaña, en 1805, cuando se registran " 270 quimones azules de 4 varas en elefante" (Autos formados por Domingo Beregaña contra Jose Bernardo Baz. México, 31-XII-1802 y 31 - 
no siempre fue uniforme: en algunos sitios se dice que la de zaraza medía "casi dos varas" de ancho, y en otros que "10 piezas de sarasa" "componen 12 de quimones enteros", lo que resulta incongruente con la medida de 8 varas del quimón ${ }^{44}$. Más allá de la dimensión específica de cada una, la ambigüedad de las fuentes no es otra que la dificultad para nombrar el tejido cuando uno se refería ya no a la pieza, sino al material con que estaba confeccionada alguna prenda. Por eso, quitando los elefantes, todos estos nombres se referían básicamente a lo mismo, o sea ${ }^{45}$ :

suele ser de varios colores, y la que tiene el campo blanco, por la mayor parte es matizada de varias flores grandes y pequeñas, todas estampadas; pero de una tinta fina, que mientras mas se lava, mas hermosa, permanente y vistosa queda. Es obraje de la China que nos traen las flotas de aquel país, por lo que en España se estiman mucho ${ }^{46}$.

Aunque esta definición de zaraza, hecha desde la perspectiva peninsular, asocie su producción con los obrajes de China, su difusión en el virreinato surge como resultado de un proceso cultural complejo, como lo revela el análisis del origen de esas piezas.

\section{Los quimones de Nueva España: de las importaciones asiáticas a la introducción de "imitaciones" europeas y su producción en América}

El estudio de este tema cuenta con el problema de la interpretación de las fuentes escritas, como ya se señaló. La documentación no siempre es clara en cuanto al tipo de pieza a la que se refiere, y no se ha conservado ninguna muestra material que pueda tomarse como referencia de su aspecto, como sucedió con muchos otros textiles que las autoridades aduaneras fiscalizaron o se enviaron como muestrario. Aun así, del

\footnotetext{
XII-1805. AGNM, Consulado, vol. 145, exp. 15, f. 222 y 247). Tal confusión se verifica ya en el siglo XVIII cuando se anuncia en la Gazeta de México, de agosto de 1788, los productos que llegaron en la Nao de la China San José de Gracia. Por entonces se refieren a "chitas ó quimones" sin distinguirlas (Gazeta de México, t. III, $\mathrm{n}^{\circ} 13,5$-VIII-1788, 131). A pesar de eso, y que la palabra exista también en portugués, la RAE no recoge este significado, apareciendo tan solo su acepción como hueso de vaca que servía para jugar, o como cosa de poco valor.

44 RAE, 1780: 949. Copia del registro de la carga del navío Buen Consejo, comandada por Juan de Casens, procedente del puerto de Cavite en Manila (Filipinas). Llegó a Cádiz el 15-VII-1767. Manila, 9-II-1767. Archivo General de Indias [España] (en adelante AGI), Contratación, 2436, N. 1, f. 172r; RAE, 1803: 708.

45 A pesar de las referencias a "elefante azul", todo indica que se trataba de un tejido blanco, como los siete bultos de manta de elefante que cargó la Compañía de Filipinas con destino al comercio africano y de la que se conserva una muestra (Quince muestras de géneros bastos de algodón y guimaras indígenas, remitidos por el gobernador de Filipinas en la fragata Astrea y Urca Santa Inés con destino al comercio africano: manta elefante. Manila, 22-XII-1778. AGI, MP-Tejidos, 34, R.12). Eso va al encuentro de lo que se dice en otro documento creado por sus funcionarios y donde se define el elefante como un "texido blanco de algodon muy ordinario para enfardar". De acuerdo a esa misma fuente las "chitas y zarazas" eran un "texido fino de algodón pintado" y los quimones "lo mismo que las chitas y zarazas" (Generos y Metales de China que conduce el Navio Buen Consejo, (ca. 1750-1800). AHN, Diversos-Colecciones, 30, N. 6). Citación retirada de RAE, 1780: 949.

$46 \quad$ RAE, 1780: 949.
} 
análisis global de los datos, resalta la reducida presencia de ejemplares indudablemente japoneses en el ajuar novohispano ${ }^{47}$.

En contrapartida, el comercio asiático proporcionó una enorme cantidad de tejidos chinos que pudieron ser del mismo tipo que importaba Japón para confeccionar kimonos, y que se hacían en China o en la India ${ }^{48}$.

Bastante más raros son los de Filipinas. La presencia de uno de esos tejidos en 1789 demuestra que existió una producción interna capaz de extenderse al exterior, compitiendo con las que venían de fuera, traídas por los sangleyes para colocarlas en el galeón ${ }^{49}$. Existen varias circunstancias que justifican esta situación. En primer lugar cabe destacar que las islas tuvieron un importante cultivo de algodón que se llegó incluso a exportar ${ }^{50}$. El surgimiento de este tipo de manufactura pudo relacionarse con el fuerte impacto de la importación de textiles protagonizada por los chi$\operatorname{nos}^{51}$. Entre estos se incluirían los de quimón, influyendo en el gusto e indumentaria autóctonos. Su demanda pudo haber incentivado interpretaciones locales y cabe la posibilidad que contaran con la colaboración de artesanos japoneses o chinos instalados en la región ${ }^{52}$. En todo caso, a finales del siglo XVIII se asistió a un estímulo a los cultivos y manufacturas de exportación impulsados por las autoridades locales y la actividad de la Compañía de Filipinas que hizo varios experimentos en la región. Esta empresa llegó a colocar sus mercancías en Nueva España, pese a que su finalidad principal fuera la de crear una conexión directa entre la península y sus territorios asiáticos, sin pasar por América ${ }^{53}$. Este modelo obedece a la misma lógica re-exportadora que ya observaron otros investigadores relativa a Inglaterra y Holanda, como ya se mencionó.

Lo más destacable es que la elaboración de estas piezas no se circunscribió a las regiones de Asia sino que se extendió a América. A finales del siglo XVIII, empezaron a hacerse ejemplares "mexicanos" y "criollos" que alcanzaron prácticamente toda la población. Su proliferación en la documentación coincide con la liberación de la manufactura de algodones pintados en 1772 y el crecimiento del sector.

Asimismo, estos materiales se siguieron importando desde otras partes del continente. Del virreinato de Nueva Granada se conocen solo unos quimones del Guárico (Venezuela) de $1785^{54}$. Eso se puede justificar por la aparición del cultivo de añil en la región durante esos años. Tales iniciativas motivarían el surgimiento de una producción local de indianillas, pero no se conocen trabajos al respecto que puedan sostener mejor esta teoría. Otra posibilidad es que su presencia ahí se justificara por el

47 Se revisaron exhaustivamente los fondos de Aduanas y Consulados del AGNM y algunos fondos de otros archivos mexicanos y españoles.

48 Consúltense los datos sobre las importaciones chinas, conformadas también por tejidos de India, concedidos por Fujita, 2009. Sobre el desarrollo del sector de pintados en China: Sadao, 1984: 17-78.

49 Díaz-Trechuelo, 1965: 351. La palabra sangley se utilizaba para designar a los chinos residentes en Manila.

50 Legarda, 1999.

51 Coo, 2014: 383-392.

52 Se sabe muy poco sobre la presencia japonesa en Manila durante el siglo XVIII y resulta difícil rastrear el impacto de la comunidad cristiana que se fijó ahí después que se expulsaran los jesuitas de Japón.

53 Solo así se entiende que Gaspar Leal, el director de la compañía, no accediera al pedido de tejidos que le hizo directamente la reina, en 1788. Según él, "las Sarasas i cherlas [que acababan de llegar a Cádiz] ni por la calidad ni el dibujo son cosa de gusto para España pero si para Nueva España à donde se destina este genero" (Documentos relativos a la Compañía de Filipinas. Cádiz, 2-V-1788. AGI, Filipinas, 987, s.f).

54 Mariana Fernanda Fernandez Munilla viuda de Simon de los Villares, vecino y del comercio que fue de esta ciudad contra Bernardo Marcelino de Villar, del comercio de Villa de Lagos, sobre pesos. Lagos, 19-XII-1785. AGNM, Consulado, vol. 40, exp. 4. 
contrabando, haciendo pasar por creaciones locales ciertas importaciones europeas o asiáticas para colocarlas legalmente en el mercado de exportación americano ${ }^{55}$.

En el Perú también se usaron este tipo de tejidos, pero no se tiene noticia de que los produjera, ni mucho menos que los enviara a Nueva España ${ }^{56}$. En realidad, los flujos entre estas dos regiones parecen haber sido en sentido inverso, encontrándose remesas de esas ropas hacia varios de sus puertos ${ }^{57}$. Algunas de esas piezas pudieron hacerse en Nueva España, como telas de indianilla y zaraza "criollas" o "pintadas en México" que compusieron la carga de esos navíos, pero otras fueron claramente manufacturadas en $\mathrm{Asia}^{58}$.

En la región rioplatense aparecen, de manera muy puntual, algunas batas asiáticas desde mediados del siglo XVIII pero no se detectaron referencias a los tejidos de quimón. Tampoco hay indicios de que desarrollara una producción propia, ni siquiera después de que se formara el virreinato y se empezaran a estimular algunos sectores productivos. En todo caso, nuestro primer acercamiento a los inventarios de bienes de Buenos Aires y los trabajos publicados con base en esa documentación sugieren que su uso no estuvo tan extendido como en Nueva España ${ }^{59}$.

La fuerte dispersión geográfica de los centros de producción identificados demuestra cómo esta moda no se circunscribió al ámbito asiático, sino que se expandió a América, donde su demanda estimuló la compra de equivalentes en otras zonas de Asia y su elaboración en los talleres locales. Tales productos se destinaban al con-

55 Pacheco, 2000: 122 y 251.

56 Antonio Barba de Cabrera residía en Lima en 1799 y por entonces tenía entre sus bienes "un poncho a la chinesca" y "ocho varas de saraza o quimon" (Archivo General de la Nación [Perú] (en adelante AGNL), Protocolos Notariales, escribano Justo Mendoza y Toledo, vol. 729, 1799, f. 421r-437r). Ya doña Mariana Gertrudis García poseía una "colgadura de quimon" (AGNL, Protocolos Notariales, escribano notariales Felix Garcia Romero, vol. 490, 1780/1781, f.507r-511r) mientras que Cayetano Martínez de Diego usó la tela para hacer "una bata con su chupin de quimon de china o sarasa" que tenía en 1776 (Instituto Riva Güero, C-123, f. 21r, 52r y 81r). La noticia más antigua de esas batas es en la región de Salta, entre el inventario del capitán Bernardo Blanco, hecho en 1745 y en el que constan una "bata de angarípola de la China forrada" que remite para un padrón de rayas, y una "bata de raso de la China azul a flores anaranjada" (Bonialian, 2014: 229).

57 En 1782 la fragata Aurora trasportó "9 piezas de quimones" al Callao (Enterado del armamento y demas municiones que ha entregado al comandante de la fragata San Jose, Bruno Heceta. Nao San Pablo, fragata San Pedro, Nuestra Señora de la Soledad, fragata La Aurora, San Juan Bautista, navio San Francisco de Padua. Acapulco, 20(?)-II-1782. AGNM, Marina, vol. 60. exp. 2, f. 192r). El mismo destino que tuvieron las " 25 colchas de quimón catreras ordinarias" llevadas en el navío Hércules (Enterado del armamento y demas municiones que ha entregado al comandante de la fragata San Jose, Bruno Heceta. Nao San Pablo, fragata San Pedro, Nuestra Señora de la Soledad, fragata La Aurora, San Juan Bautista, navio San Francisco de Padua. Acapulco, $27-$ III-1782. AGNM, Marina, vol. 60. exp. 2, f. 224r). El navío San Pablo trasportó “18 quimones de segunda, 451 piezas de quimones de tercera" para Paita y Lima (Enterado del armamento y demas municiones que ha entregado al comandante de la fragata San Jose, Bruno Heceta. Nao San Pablo, fragata San Pedro, Nuestra Señora de la Soledad, fragata La Aurora, San Juan Bautista, navio San Francisco de Padua. Acapulco, 2-VII-1782. AGNM, Marina, vol. 60. exp. 2, f. 273). El navío nombrado Nuestra Señora de la Soledad y Las Ánimas condujo "2 quimones de primera, 3 quimones de segunda" para Panamá, (Enterado del armamento y demas municiones que ha entregado al comandante de la fragata San Jose, Bruno Heceta. Nao San Pablo, fragata San Pedro, Nuestra Señora de la Soledad, fragata La Aurora, San Juan Bautista, navio San Francisco de Padua. Acapulco, 10-II1782. AGNM, Marina, vol. 60. exp. 2, f.197r.).

58 Solo en el año de 1783 se transportaron: en el navío Nuestra Señora de Loreto "14 quimones de colores" desde Sonsonate y Tumaco hacia Paita, en El Belencito "dos quimones ordinarios de China" desde Acapulco a Piura, en el Santa Ana "7 quimones de primera" y "ocho quimones de tercera" desde Acapulco a Lima. (Bonialian, 2014: 101-195. Fuente citada: Archivo Nacional de Lima [en realidad Archivo General de la Nación, Perú], Aduana, Paita, C 16, 1193-92).

59 El mercader de Buenos Aires, Don Manuel de Escalada Bustillos, tenía “tres batas de China para mujer" en 1774 (Bonialian, 2014: 236). Véase también el ya mencionado caso de Salta en la nota número 16. 
sumo interno e igualmente a la exportación hacia otras regiones del continente, por lo que sería interesante averiguar si algunos centros adaptaron sus creaciones a las demandas del mercado exterior.

Por lo general, el proceso de expansión de esos textiles tuvo varios focos de desarrollo que se retroalimentaron para responder a las necesidades estéticas del consumidor local o del mercado de exportación. Así, el ideal japonés fue solo una de las acepciones que conocieron dichas telas hechas en prácticamente cualquier parte del mundo. Éstas gustaban porque eran "al modo de la China" y se usaban para construir escenarios achinados en los que el elemento japonés confería un prestigio adicional, como producto de un pueblo considerado superior a los demás asiáticos ${ }^{60}$. Curiosamente, no se detectó ningún quimón o quimono europeo.

En diferentes puntos de Europa emergió desde muy pronto una pujante manufactura de algodón pintado y algunos de esos talleres exportaron sus creaciones a Nueva España. En ese ámbito, el análisis documental reveló una preponderancia de los ejemplares catalanes e ingleses, los únicos que aparecen con la designación del origen. Si el comercio de los primeros disfrutaba del apoyo y la connivencia de la Corona, los segundos se introducían ilegalmente a finales del siglo XVIII, causando problemas a la venta de las manufacturas peninsulares ${ }^{61}$.

En esas ocasiones, los tejidos se designaron por términos equivalentes al de quimón. Su conexión simbólica más directa era la India y la ciudad de Surat, de las que parece haber derivado respectivamente su designación de indianilla y zaraza. Tal asociación servía en Japón para nombrar como sarasa a esos tejidos y, por el momento, resulta imposible determinar si penetró así en el vocabulario castellano. En todo caso, esto sugiere que el lenguaje novohispano distinguió dos flujos comerciales y culturales: uno Atlántico y otro Pacífico. Así, cuando las personas se referían a las producciones "achinadas" de Europa y a las que se fabricaban a su semejanza, se observa una propensión para designarlas respectivamente de "zarazas" y "zarazas criollas" "62. Paralelamente, cuando se introducían desde Asia, o estaban hechas a su imitación en América, se optaba sobre todo por el término "quimón", posiblemente porque llegaron inicialmente en la forma de trajes, aunque luego se emplearan con otras finalidades.

\section{Las aplicaciones del quimón}

En la sociedad virreinal, la apariencia sirvió de telón para organizar castas, distinguir rangos y definir estatutos, por lo que el refuerzo de los impulsos visuales señaló las diferencias impuestas políticamente. El medio más directo para expresarlo fue la moda, regulada permanentemente por leyes suntuarias que establecieron los límites

60 Véanse las consideraciones hechas en Sanabrais, 2009.

${ }_{61}$ Sobre la producción de textiles pintados en Cataluña para el abasto americano véase: Vicente, 2006. Sobre el contrabando de zarazas inglesas en el virreinato a inicios del s. XIX consúltense los expedientes: Indulto de Juan Manuel Sanchez acusado del contrabando de zaraza inglesa. Puebla, Tlaxcala, 1811. AGNM, Alcabalas, vol. 114, exp. 24, f. 350-355. Causa de Nicolas Maria Zaragoza acusado de introducir zaraza inglesa, 1803-1806. AGNM, Alcabalas, vol. 57, exp. 5, f. 88-166.

62 La expresión "zaraza criolla" aparece recogida por ejemplo, en el registro de la mercancía de la fragata Aurora (Enterado del armamento y demas municiones que ha entregado al comandante de la fragata San Jose, Bruno Heceta. Nao San Pablo, fragata San Pedro, Nuestra Señora de la Soledad, fragata La Aurora, San Juan Bautista, navio San Francisco de Padua. Acapulco, 20(?)-II-1782. AGNM, Marina, vol. 60. exp. 2, f. 192). 
en los que debería definirse la apariencia de cada uno de los grupos. En este sentido, las telas nombradas a la japonesa sirvieron para diseñar cuerpos diferenciados en la pintura costumbrista novohispana. Esta expresa un nivel de realidad más asociado a las percepciones simbólicas y, en ese contexto, el quimón sirvió como demarcador de estatus entre las diferentes castas.

La originalidad con que cada sector vistió o se representó con dichas piezas dependió de la norma instituida y, sobre todo, de su capacidad económica para violarla. En este ámbito, resalta la enorme repercusión de los textiles introducidos por la Nao de la China y que, al contrario de lo que se defendió durante mucho tiempo, no siempre fueron géneros de lujo. La mayoría no tuvo una calidad destacable, y su bajo precio relativamente a los congéneres europeos favoreció la generalización de ciertos consumos. Eso sucedió en relación a la seda, como lo destacó recientemente Bonialian y, sobre todo, con los algodones ${ }^{63}$.

En el virreinato el patrón de medida de las piezas permitió que, además de batas, estas sirvieran para confeccionar casullas y trajes masculinos de tres piezas, o sea, calzón, chaleco y chaqueta ${ }^{64}$. En ocasiones se vendieron en fracciones más pequeñas, como las "110 medias piezas de quimones que hacen 55 enteras" que, en 1767 , llegaron a Cádiz en uno de los navíos de la Real Armada ${ }^{65}$.

Por lo general, los tejidos alcanzaron una gran difusión en la confección de atuendos así de hombre como de mujer, y complementos para la casa. La aplicación más común fue para enaguas, probablemente porque su calidad permitía que se lavaran sin desteñir, tornándolos especialmente útiles para ropas que tenían contacto más próximo con el cuerpo y necesitaban limpiarse con mayor frecuencia ${ }^{66}$. Además, su durabilidad permitió alimentar un mercado de segunda mano, apareciendo en casi todos los listados de bienes empeñados en tiendas de pulpería que en algún momento necesitaron la intervención del Consulado de Mercaderes de México ${ }^{67}$. Por mencionar apenas un ejemplo, en 1794, la "Tienda del Sol" (Ciudad de México) tenía varios ejemplares de este tipo empeñados por diferentes personas y su precio raramente superó los 6 pesos $^{68}$.

La enagua fue un complemento fundamental del vestuario femenino, independientemente del grupo social a que perteneciera. Se vestía debajo de la falda y estuvo disponible en varios modelos con distintos precios. Las que se hicieron en quimón aparecen entre los bienes de mujeres tan distinguidas como Doña Isabel de Puertas Sánchez y Tagle, hija legítima del coronel Don Juan Francisco de la Puerta. Al casarse con Don Vicente de Yturribarria, alcalde mayor de Tecayan, llevó entre su dote "seis pares de dichas [naguas] de Sarasas y Quimones con sus Puntas encajes, y

63 Véase por ejemplo la documentación generada por el Consulado de México, dónde se discutió ampliamente el tema durante el siglo XVIII (Expedientes del consulado y comercio, 1709-1759. AGI, México, 2501, s.f). Sobre el comercio de sedas asiáticas consúltese Bonialian, 2014.

64 AGNM, Grupo 42, vol. 18, ex. 7, f. 442-448, citada por Slack, 2012. No se pudo localizar este documento porque el grupo 42 corresponde actualmente a la sección de "Donativos y Préstamos", y el vol. 18 trata sobre otras materias.

65 Copia del registro de la carga del navío Buen Consejo, comandada por Juan de Casens, procedente del puerto de Cavite en Manila (Filipinas). Llegó a Cádiz el 15-VII-1767. Manila, 9-II-1767. AGI, Contratación, 2436, f.172r.

66 Sobre el impacto de los algodones pintados en la manufactura de ropa interior: Riello, 2010a: 11.

${ }_{67}$ Se analizaron exhaustivamente los documentos disponibles e inventariados en este fondo documental hasta 2014.

68 Inventario de la tienda que llaman del Sol, perteneciente a Juan Rubin de Celis que ha sido entregada a José Anaya. México, 15-X-1794 a 18-X-1794. AGNM, Archivo Histórico de Hacienda, vol. 491, exp. 67. 
listones ya usadas apreciadas en sesenta pesos"69. Una vez más se asocia el quimón a la zaraza y se describen unas prendas espectaculares. Rápidamente se imaginan unas enaguas con motivos estampados por toda la superficie y rematadas, en la zona inferior, por puntas triangulares de encaje que se solían importar de Europa para adornar los vestidos más refinados. Eso, por no hablar de la cinta de seda, o listón, que podría venir del viejo continente, de Filipinas, o incluso de la Mixteca que contó con una producción de seda importante.

A pesar de que algunos de estos atuendos tuvieran una calidad destacable, con acabados que no todos se podrían permitir, resulta difícil reconocerlos en los retratos de las damas de la élite. Entre las indígenas tuvieron una función decorativa más destacada, quienes dejaban sobresalir una parte del tejido por debajo del huipil o entre las aperturas laterales de la falda. De esa manera aparecen pintadas por Luis de Mena en el cuadro De mulato e india, calpamulato $^{70}$.

Con quimón se hicieron igualmente basquiñas, que es una especie de saya para mujeres. En la parte de arriba tienen unos pliegues que forman la cintura y por la parte inferior ganan mucho vuelo. Las encontramos entre las pertenencias del piloto de la Real Armada, Don José Camacho ${ }^{71}$. En la iconografía costumbrista, estas se asociaron a las españolas y a todas las esposas de peninsulares, independientemente de su categoría. En el primer caso, ellas aparecen sobre todo con tejidos pintados en tonos oscuros sobre los que se estamparon motivos florales de colores sobrios, al igual que sucedía en España. Eso se observa en los cuadros De castizo y española, español, de José de Ibarra o en el De español y morisca, albino de Juan Patricio Morlete $^{72}$. Por el contrario, las mujeres de condición inferior se representan preferentemente con basquiñas de quimón de fondo blanco, con flores de colores contrastantes y algún que otro insecto. Así aparecen en las obras de Miguel Cabrera, adornando el cuerpo de las parejas mulatas y albinas, en la serie identificada por Ilona Katzew pertenecientes a una colección privada ${ }^{73}$.

Además de basquiñas, se detectó la designación genérica de faldas de quimón cuyo precio varió mucho en función de la procedencia y la calidad del trabajo, alcanzando la suma considerable de 20 pesos que tuvieron algunos vestidos más sencillos. Esas ropas se extendieron entre las mujeres humildes, con modelos más simples y normalmente de un único color, como en el cuadro De negro e india de Miguel Cabrera $^{74}$. En esas pinturas se eligieron los textiles pintados en tonos de azul o de rojo, asociándolos simbólicamente a la recolección local de añil y de grana cochinilla usados en las manufacturas de pintados local. Eso no significó que las prendas fueran necesariamente de menor prestigio y baratas, pudiendo un simple "quimón de segun-

69 Recibo de dote: Vicente de Yturribarria y Urquijo, alcalde mayor y teniente de capitán general de la provincia de Jicayán dice que confiesa haber recibido del padre de Ysabel de Puertas Sanches, prometida del otorgante, dote que suma la cantidad de 2,659 pesos, 12-X-1758. Archivo General de Notarías de Oaxaca [México] (en adelante AGNO), vol. 100, f. 83, notario Joachin de Amador, 1758, Antequera-Oaxaca.

70 Colección del Museo de América de Madrid (en adelante MAM), nº inventario 00026.

71 Autos de inventarios hechos a los bienes que en este pueblo quedaron por fallecimiento de Don Jose Camacho, teniente de navio graduado y piloto primero de la Real Armada, con destino en el departamento de San Blas. Tepic, 16-IV-1795. AGNM, Filipinas, vol. 18, exp. 4, f. 117.

72 Colección del MAM, nº inventario 1995/04/03 y de Los Ángeles County Museum of Art (en adelante LACMA), $\mathrm{n}^{\mathrm{o}}$ inventario M.2011.20.1, respectivamente.

73 Katzew, 2004.

74 Colección del MAM, $\mathrm{n}^{\circ}$ inventario 00006. 
da azul mexicano" alcanzar el precio de $60 \operatorname{pesos}^{75}$. Destaca aún la vistosa falda que lleva la albina casada con un español, pintada por Juan Patricio Morlete ${ }^{76}$. Su patrón recuerda a la decoración de unas muestras enviadas por el virrey de Nueva España, conde de Revillagigedo, al Consejo de Indias ${ }^{77}$.

Morlete pudo inspirarse en telas de producción local para hacer esos cuadros, aunque también los textiles europeos y asiáticos usaron colorantes de origen novohispano que se exportaron con gran éxito hacía España y Filipinas ${ }^{78}$. Tal vez sea ese el caso de los "18 quimones entrefinos, de pinturas encarnadas, y bien pobladas" que Joseph Antonio Pérez compró en Acapulco para vender en su tienda ${ }^{79}$.

El vestido de mujer fue un atavío de distinción que no estuvo al alcance de cualquier bolsillo. Tómese como ejemplo el de quimón con blonda, de Doña Josefa de Ogazón, valorado en 25 pesos en su recibo de dote $(1793)^{80}$. Su precio permite afirmar que, en el siglo XVIII, muy difícilmente las clases populares los pudieron adquirir y eso se refleja también en la iconografía. Para hacer esas prendas estampadas se emplearon dos técnicas. La primera consiste en imprimir motivos florales, como se ve en el cuadro de Miguel Cabrera De español y morisca, albino ${ }^{81}$; mientras que la segunda es en un patrón de bandas verticales que admite la inclusión de diseños vegetales, como el vestido representado por Francisco Clapera en De mulato y española, morisco ${ }^{82}$.

Entre los hombres, el uso del quimón fue bastante más escaso. Se sabe que sirvió para la confección de trajes de tres prendas pero en la documentación se ha detectado únicamente en casacas y casaquitas que valían menos de un peso $^{83}$. Es posible que se usaran también como medias, como las "nueve medias dichas de quimon" que llevó entre su equipaje Don Patricio del Villar cuando embarcó en América para Sevilla a su regreso de Manila, en $1767^{84}$.

75 Autos ejecutivos contra Francisco Escudero, mercader viandante de México, acusado por fraude por Alberto Herrera, Elenterio López y Ángel González, del comercio de México, y Manuel Antonio del Valle, vecino y del comercio de Veracruz, ya que no pago los productos que le fiaron los demandantes. Acambaro, 4-XII-1793. AGNM, Consulado, vol. 217, exp. 2, f. 398.

76 Colección del LACMA, $\mathrm{n}^{\mathrm{o}}$ inventario M.2011.20.2.

77 Muestras de Indianas y sedas. México, 30-VIII-1793. AGI, MP-tejidos,15. Duplicados del virrey don Manuel Antonio Flores, por la vía reservada de la Secretaría de Estado de Hacienda. México, 30-VIII-1793. AGI, México, 1554.

78 Véase, por ejemplo la exportación de grana cochinilla para Filipinas, anunciada en la Gazeta de México, Suplemento, t III, no 29, 14-IV-1789, 299. Sobre su impacto en las manufacturas textiles de Europa, Asia y Medio oriente: Sánchez Silva - Suárez Bosa, 2006; Riello, 2010a; Riello y Parthasarathi, 2009: 291-306; Pérez, 2013; Schwartz, 1996; Larrère, 1992: 95-140; Bryan de Souza, 2009; Fukasawa, 1987; Lemire, 2003 b.

79 Memoria de los efectos, y Generos de china que nezesito para el surtimiento de la tienda de mi Amo D.n Jph Antonio Perez y Crespo. Acapulco, 28-III-1770. AGNM, Archivo Histórico de Hacienda, vol. 1402, exp. 5, f. 33.

${ }^{80}$ Recibo de dote para ayuda de las cargas matrimoniales entre Jose Ximeno Bohorquez y Varela Josefa de Ogazor y Maga, 11-XII-1793. AGNO, vol. 70, f. 180, notario Joseph Álvarez, 1793, Antequera-Oaxaca.

81 Colección LACMA, $n^{\circ}$ inventario M.2014.223.

82 Colección del Denver Art Museum, $\mathrm{n}^{\mathrm{o}}$ inventario 2011.428.5.

83 Cesion de bienes hecha por Ignacio Olascuaga, vecino del comercio del Real Angangueo. Real de Angangueo. México, 26-II-1806. AGNM, Consulado, vol. 152, exp. 1, f. 234r. Inventario de la tienda que llaman del Sol, perteneciente a Juan Rubin de Celis que ha sido entregada a José Anaya. 15-X-1794 a 18-X-1794. AGNM, Archivo Histórico de Hacienda, vol. 491, exp. 67. Autos formados por Domingo Sanchez contra Juan Doderz por la tienda de pulperia ubicada en la Calle del Reloj. México, 21-I-1800 A 24-I-1800. AGNM, Consulado, vol. 192 , exp. 4.

84 Copia del registro de la carga del navío Buen Consejo, comandada por Juan de Casens, procedente del puerto de Cavite en Manila (Filipinas). Llegó a Cádiz el 15-VII-1767. Manila, 9-II-1767. AGI, Contratación, 2436, N. 
La asociación entre la descripción de los atuendos de quimón en los inventarios de bienes y su identificación en los cuadros de castas ha proporcionado una idea más clara de cómo serían esos tejidos y de su difusión entre los varios sectores de la población. No obstante, tales representaciones no pueden considerarse una imagen fiel de la sociedad, sino que "son producto de prácticas visuales inmersas en narrativas reguladas que sirven ambiguamente tanto para captar como para construir los cuerpos", como afirma Carlos López Beltrán ${ }^{85}$. Por eso deben entenderse en el ámbito para el que se crearon, o sea, para darse a ver y ser vistas por otros ${ }^{86}$. En este estilo pictórico, los casamientos entre personas de diferentes castas expresaron simbólicamente los grados de conexión a la tierra de origen. Así, las españolas se visten con quimones muy similares a los usados en Europa, mientras que las demás castas optan por patrones decorativos diferentes. Como imágenes idealizadas, se utilizaron los grupos sociales más bajos para encarnar las particularidades novohispanas, omitiendo las adaptaciones originales que surgieron entre los más ricos, y que se perciben en las descripciones de las prendas recogidas en la documentación escrita.

Por todo lo anterior no se puede estar de acuerdo con la tesis que sostiene Julieta Pérez Monroy de que "lo representativo del Reino" se encuentra "en los trajes

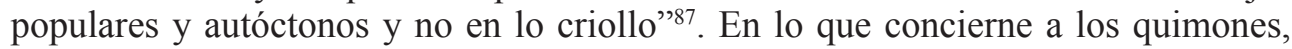
la originalidad de las composiciones decorativas tuvo varias expresiones en las que contribuyeron todos los sectores. Desde sus universos simbólicos y capacidad adquisitiva, seleccionaron y trasformaron los elementos decorativos asiáticos que mejor respondieron a sus inquietudes. Su exponente máximo fueron los quimones criollos, hechos localmente bajo iniciativas artesanales promovidas por los grupos menos vinculados a los intereses metropolitanos, no necesariamente más pobres.

Así, las preferencias textiles achinadas se diferenciaron de las de la metrópolis porque las contextualizaciones de lo exótico asumieron formas distintas en cada una de las provincias del imperio. En Nueva España, tal singularidad se nutrió del desarrollo interno de la manufactura de algodones pintados y de un comercio interregional que los colocaba en el mercado a un precio bastante más competitivo que el de sus congéneres europeos. Curiosamente, este distanciamiento "estético" contó también con la connivencia de los talleres peninsulares que desarrollaron una producción exclusiva para la exportación, capaz de competir en un mercado inundado por telas "de la tierra", asiáticas y europeas ${ }^{88}$. Lo que todavía no se ha averiguado es si el aprecio por determinados patrones de inspiración asiática resultó más una atracción por los motivos de los tejidos designados como "chinos", o por las interpretaciones "achinadas" europeas que se sometieron a ligeras transformaciones para seguir gozando de un prestigio especial entre las élites del virreinato. En nuestra opinión aquí reside la clave de la moda criolla y de su singularidad.

1, f. 98 .

85 López Beltrán, 2008: 301.

${ }^{86}$ Varios autores defienden que una gran parte de estas pinturas se destinaba a la exportación. En concreto se encontró la referencia a 16 "pinturas también en Cobre q.e representa las varias castas del vaxo Pueblo de Mexico" que en 1778 se condujeron a España en "razon de Generala Equipaxe y sobra de Rancho del S.or General deça Flota Don Antonio de Ulloa". Cabe recordar que 16 era precisamente el número de representaciones que solían componer una serie de cuadros de castas. Así las generalas sirvieron para trasportar equipaje pero esencialmente productos destinados al comercio, con los que la tripulación completaba su sueldo (Manifestaciones de equipajes, 1778. AGI, Contratación, 5806B).

87 Pérez Monroy, 2001: 131.

88 Sobre los estampados de Valencia véase Franch Benavent, 1991. 
Además de atuendos, los quimones sirvieron para confeccionar ropa de casa, tal como sucedió en Europa. Ante la llegada de los primeros ejemplares, se les reconoció las mismas utilidades que tenían en la India en la decoración arquitectónica y de la casa. En el virreinato, ese tipo de aplicación quedó registrado en la iconografía pero, en la documentación escrita solo se ha detectado a partir de finales del siglo XVIII y/o inicios del XIX ${ }^{89}$. Se trata esencialmente de inventarios de empeños a los que se acudía regularmente para lograr algún dinero que se acababa por gastar en la misma tienda. En esos lugares aparecen los quimones regularmente con la forma de cortinas, sábanas, sobrecamas o colchas, cuyo aspecto se pudo rescatar en un exvoto de 1778 , en el que se distinguen unas mujeres de indumentaria humilde en torno a una cama cubierta por un lienzo blanco estampado de azul ${ }^{90}$.

\section{Conclusiones}

Los resultados de esta investigación ponen de manifiesto la importancia de incluir el Pacífico en los estudios de historia global para percibir cómo la circulación condicionó el comercio, el gusto y la manufactura de tejidos de algodón pintados en Nueva España.

En lo que concierne al primer punto, las relaciones privilegiadas del virreinato con Manila le posibilitaron el acceso permanente a esos géneros producidos en Asia, volviendo insostenible la idea de que se trató de una región marginal. Ni lo fue el virreinato, ni su situado filipino que estuvo permanentemente conectado con las redes de comercio inter-asiático y frecuentemente fue permeable a la presencia de mercaderes europeos. Los portugueses son solo una de las comunidades que logró entrar en esos circuitos y vender sus productos en Manila, incluso después del período de unión de coronas. Las factorías de Portugal en la India la colocaron en una posición privilegiada en el comercio de esos materiales pero aún no ha habido ocasión de analizar detenidamente la naturaleza de las transacciones protagonizadas por esos hombres en las islas.

La gran mayoría de los ejemplares asiáticos que llegaban a Nueva España con denominación de origen eran de China. Estos pudieron producirse en la India y ser comercializados por los sangleyes instalados en Filipinas, o estar hechos directamente en China a su semejanza. Los súbditos del Imperio del Medio dominaron por mucho tiempo este negocio y llegaron a desarrollar una producción interna que pudo exportarse a Manila o a Japón, donde tuvieron que lidiar con la competencia lusitana y holandesa. La atracción que causaron esos tejidos motivó la creación de interpretaciones niponas que se usaban en la confección de kimonos, los mismos por los que se interesaron los occidentales. Al parecer, se desarrolló una producción

89 Lemire, 2003b: 65-68; 2003a; Riello, 2010a: 13.

90 Cortina: Avalúo de las prendas de la tienda de pulquería que se halla situada en la esquina de la calle de la Misericordia, la que nombran del Sol, jurisdicción de la Parroquia del Sagrario, de la que es dueño Juan Rubín de Celiz, quien tiene pedida licencia. México, 12-III-1795 a 14-III-1795. AGNM, Archivo Histórico de Hacienda, vol. 491, exp. 35. Sábana: Que hace Silvestre de la Presa de las prendas que se hallan en la tienda del Puente de Santo Domingo la que es de Bartolomé Ricardo. 20-VII-1797. AGNM, Archivo Histórico de Hacienda, vol. 491, exp. 51. Sobrecama: Autos formados por Domingo Sanchez contra Juan Doderz por la tienda de pulperia ubicada en la Calle del Reloj. México, 21-I-1800 a 24-I-1800. AGNM, Consulado, vol. 192, exp. 4, f. 32. Ex voto: Luque Agraz, 2010: 107. 
destinada exclusivamente a la exportación y así llegaron los primeros quimones a Nueva España, bajo la forma de bata de quimono. La atracción por esas piezas pudo haber ocasionado la importación directa de los textiles de algodón pintado japoneses, pero las relaciones políticas y comerciales con esa región condicionaron su presencia en el ajuar novohispano hasta tal punto de no dejar constancia en las fuentes. Hasta inicios del siglo XIX sus tejidos se consideraron de mejor calidad pero llegaban desde otras partes de Asia y también de América. A la par que se importaban quimones del Guárico (Venezuela), crecía el sector de indianillas y pintados. En esos talleres y en sus creaciones achinadas se expresaba de manera particular la convergencia entre una influencia asiática directa y otra que llegaba por intermedio de los achinados europeos. Por eso sería interesante analizar más detenidamente estas creaciones en el futuro.

En lo que concierne al uso, las fuentes escritas e iconográficas hacen posible afirmar que los quimones orientales se difundieron de modo substancial entre casi toda la población, sobre todo a partir de mediados del siglo XVIII, surgiendo como una opción interesante a los tradicionales elementos de distinción social. Estos tejidos estuvieron siempre disponibles en gran cantidad y a precios bastante asequibles, volviéndose rápidamente una alternativa para los grupos sociales intermedios. Desde los indios a los criollos, todos acudieron a estos materiales para construir la identidad de su apariencia. Se eligieron distintas decoraciones y calidades para marcar las diferencias entre unos y otros, con especial destaque para los ejemplares de algodón estampados. Los precios variaron bastante en función de los acabados y seguramente también de su origen, lo que solo en algunos casos se pudo determinar.

Se creó así una demanda que tuvo como desenlace el desarrollo de las manufacturas de indianillas americanas y españolas. Por lo general, el mercado virreinal tuvo unas características muy peculiares, con expresiones más coloridas y vistosas que en la metrópolis, por decirlo de alguna manera. Además, en el quimón convergía una larga tradición de mantas de algodón indígenas -a veces decoradas con diseños hechos por pintaderas de barro- con los nuevos influjos comerciales y las novedosas formas de estructurar el trabajo.

En suma, los quimones resumen de forma muy particular los flujos comerciales y artísticos entre varios continentes, manifiestos en la decoración del cuerpo y de las casas del virreinato. Estos intercambios se hicieron presentes en la manera de nombrar los tejidos "a la japonesa", asociándolos con otros tipos inicialmente importados de la India y luego hechos en otras regiones. Se sustenta así la idea de que su designación se debe más al prestigio de los materiales que llegaban de Japón que propiamente a la proliferación de modelos de inspiración nipona. En todo caso, si en Japón el patrón de referencia para hacer sarasas fue la India, entonces hablar de influencia japonesa en los quimones novohispanos es, fundamentalmente, referirse a una matriz con origen en la India. Así se vincularon a Japón en el lenguaje castellano y participaron en la conformación de una estética achinada en Nueva España.

En pleno siglo XVIII, los tintes y dibujos con que se pintaron, o incluso las técnicas empleadas en esos procesos, resultaron del "mundo en movimiento" de que habla Russel Wood $^{91}$. Eso hizo posible que en Europa y Asia se emplearan la grana y el añil americanos en los talleres de algodón pintado, a la par que en el virreinato este sector usara 
los mismos tintes sobre algodones asiáticos ${ }^{92}$. La decoración, estuviera hecha en Asia o en otra región, se adaptó a las demandas del consumidor final, que prefirió los diseños florales inspirados en los textiles de India, incluso cuando se designaban "a la japonesa". El interés por esos modelos originó interpretaciones también en Europa por lo que resulta difícil establecer si esta tendencia en la moda novohispana, que alcanzó todos los estratos sociales, estuvo más condicionada por sus relaciones comerciales directas con Filipinas o por el deseo de seguir las últimas novedades de la metrópolis y de las grandes ciudades europeas. En todo caso, los gustos en estas dos regiones del Imperio español fueron marcadamente diferentes. Solo así se entiende la preocupación de la Casa de la Contratación por las muestras de tejido hechas al otro lado del Atlántico y que algunas manufacturas peninsulares desarrollaran una producción adaptada a la exportación.

\section{Referencias bibliográficas}

Alemany y Bolufer, José. “Quimon”. En Diccionario de la lengua española. Barcelona: Ramón Sopena, 1917, 1402.

Antunes, Luis. "Têxteis e metais preciosos: novos vínculos do comércio indo-brasileiro, 1808-1820”. En O Antigo Regime nos trópicos: a dinâmica imperial portuguesa (séculos XVI-XVIII), editado por Gouvêa, Maria de Fátima - Fragoso, João - Bicalho, Maria Fernanda. Rio de Janeiro: Civilização Brasileira, 2001, 379-420.

- "O comércio com o Brasil e a comunidade mercantil em Moçambique (séc. XVIII)". Dimensões, $\mathrm{n}^{\circ} 19$ (2007), 207-220.

Arias Estrada, Walter Octávio. “Desarrollo textil en la Ciudad de México 1790-1817: La fábrica de Pintados de Francisco Iglesias i Capdevila”. En XIV Encuentro de Latinoamericanistas Españoles: congreso internacional, editado por Rey Tristán, Eduardo - Calvo González, Patricia. Santiago de Compostela: Universidade de Santiago de Compostela, 2010, 509515.

- Catalanes en Nueva España, 1790-1820. Emigración y Comercio. Tesis Doctoral, Universitat Pompeu Fabra, 2013.

Armella de Aspe, Virginia. "La influencia asiática en la indumentaria novohispana". En La presencia novohispana en el Pacífico Insular, editado por Barrón, María Cristina. México: Universidad Iberoamericana, 1992, 51-64.

Armitage, David - Bashford, Alison. The Pacific and its place in global history. Pacific histories: ocean, land, people. Basingstoke: Palgrave Macmillan, 2013.

Berdan, Frances - Durand Forest, Jacqueline. Matrícula de tributos: (Códice de Moztezuma): Museo Nacional de Antropología, México (COD.35-52). Graz: Akademische Drmck, 1980.

Berg, Maxine. "In pursuit of luxury: global history and British consumer goods in eighteenth century". Past \& Present, vol. 182, no 1 (2004), 85-142. DOI: 10.1093/past/182.1.85

- Luxury and pleasure in eighteenth-century Britain. Oxford: Oxford University Press, 2005. DOI: http://dx.doi.org/10.1093/acprof:oso/9780199215287.001.0001

- "Quality, cotton and the global luxury trade". En How India clothed the world, The World of South Asian Textiles, 1500-1850, editado por Riello, Giorgio - Roy, Tirthankar. Leiden: Brill, 2009, 391-414.

92 Sobre los intercambios técnicos y el uso de la cochinilla y el índigo en las manufacturas de pintados europeas y asiáticas: Riello, 2010a. 
Berg, Maxine - Gottmann, Felicia - Hodacs, Hanna - Nierstrasz, Chris (eds.). Goods from the East, 1600-1800: Trading Eurasia. Nueva York: Palgrave Macmillan, 2015.

Bernabéu, Salvador - Martínez Shaw, Carlos (eds.). Un océano de seda y plata: el universo económico del Galeón de Manila. Sevilla. CSIC, 2013.

Bonialian, Mariano. China en la América colonial: bienes, mercados, comercio y cultura del consumo desde México hasta Buenos Aires. México: Instituto Mora, 2014.

Bryan de Souza, George. "Country Trade and Chinese Alum: Raw Material Supply in Asia's Textile Production in the Seventeenth and Eighteenth Centuries". Revista de Cultura, $\mathrm{n}^{\circ}$ 11 (2004), 136-153.

- "The French Connection: Indian Cottons and Their Early Modern Technology". En How India clothed the world, The World of South Asian Textiles, 1500-1850, editado por Riello, Giorgio - Roy, Tirthankar. Leiden: Boston Brill, 2009, 347-363.

Campo, José Roberto. A China no Brasil: influências, marcas, ecos e sobrevivências chinesas na sociedade e na arte brasileiras. Campinas. Unicamp, 1999.

Coo, Stéphanie Marie. Clothing and the colonial culture of appearances in nineteenth century Spanish Philippines (1820-1896). History: Université Nice Sophia Antipolis, 2014.

Dalby, Liza Crihfield. Kimono: Fashioning Culture. Seatle: University of Washington Press, 2001.

Del Castillo, Andrés. "Textiles de la India para gustos mexicanos. El comercio de paliacates desde Pulicat, India, siglos XVI-XIX”. En A 500 años del hallazgo del Pacífico. La presencia novohispana en el Mar del Sur, editado por Yuste López, Carmen - Pinzón Ríos, Guadalupe. México: UNAM, 2016, 251-274.

Del Río, Ignacio. Estudios históricos sobre la formación del norte de México. México: UNAM, 2009.

De Vrie, Jan. The Industrious Revolution: Consumer Behaviour and the Household Economy, 1650 to the Present. Cambridge: Cambridge University Press, 2008.

Díaz-Trechuelo, María Lourdes. La Real Compañía de Filipinas. Sevilla: Escuela de Estudios Hispano-Americanos, 1965.

Fisher, Abby Sue. Mestizaje and the Cuadros de Castas: Visual Representations of Race, and Dress in Eighteenth Century Mexico. Tesis Doctoral, University of Minnesota, 1992.

Franch Benavent, Ricardo. "Las primeras empresas de estampados de indianas en la Valencia del siglo XVIII'. En L'impresa. Industria, commercio, banca. Secc. XIII-XVIII, Atti della 'Ventiduesima Settima di Studi', editado por Cavaciocchi, Simonetta. Florencia: Le Monnier, 1991, 385-392.

Fujita, Kayoko. "Japan Indianized: the material culture of imported textiles in Japan, 15501850". En The spinning world: a global history of cotton textiles, 1200-1850, editado por Riello, Giorgio - Parthasarathi, Prasannan. Oxford: Oxford University Press, 2009, 181-203.

Fukasawa, Katsumi. Toilerie et commerce du Levant d'Alep à Marseille. Paris: CNRS. 1987. Gaastra, Femme. "The textile trade of the VOC the Dutch responde to the english challenge". South Asia: Journal of South Asian Studies, no 19 (1996), 85-95. DOI: http://dx.doi. org/10.1080/00856409608723273

Gluckman, Dale Carolyn - Takeda, Sharon Sadako. When Art Became Fashion: Kosode un Edo-period Japan. Los Angeles: County Museum of Art, 1992.

Hernández Jaimes, Jesús. "El comercio de algodón en las cordilleras y costas de la mar del sur de Nueva España en la segunda mitad del siglo XVIII" En Mercaderes, comercio y consulado de Nueva España en el siglo XVIII, editado por Del Valle Pavón, Guillermina. Ciudad de México: Historia Económica e Instituto Mora, 2003, 224-256. 
Hobsbawm, Eric. Industry and Empire: From 1750 to the Present Day. London: Penguin Books, 1968.

Inikori, Joseph. Africans and the Industrial Revolution in England: a study in international trade and economic development. Cambridge: Cambridge University Press, 2002. DOI: http://dx.doi.org/10.1017/CBO9780511583940

- "English versus Indian Cotton Textiles: The Impact of Imports on Cotton Textile Production in West Africa". How India clothed the world, The World of South Asian Textiles, 1500-1850, editado por Riello, Giorgio - Roy, Tirthankar. Leiden: Boston Brill, 2009, 85-114.

Kamada, Yumiko. "The Use of Imported Persian and Indian Textiles in Early Modern Japan". En Textile Society of America Symposium Proceedings. Washingthon, Paper 701, 2012, $1-12$.

Katzew, Ilona. La pintura de castas. Representaciones espaciales en el México del siglo XVIII. Madrid: Turner, 2004.

Kobayashi, Kazuo. Indian Cotton Textiles and the Senegal River Valley in a Globalising World: Production, Trade and Consumption, 1750-1850. Tesis Doctoral, London School of Economics, 2016.

Larrère, Catherine. L'invention de l'economie au XVIII siècle du droit naturel á la physiocratie. Paris: Presses Universitaires de France, 1992.

Legarda, Benito J. After the Galleons: Foreign Trade, Economic Change and Entrepreneurship in the Nineteenth-Century Philippines. Quezon City: Ateneo de Manila University Press, 1999.

Lemire, Beverly. Fashion's Favourite: the cotton trade and the consumer in Britain, 16601800. Oxford: Oxford University Press, 1991.

- "Fashioning Cottons: Asian trade, domestic industry and consumer demand 1660-1780". En The Cambridge History of Western Textiles, vol. 2, editado por Jenkins, David. Cambridge: Cambridge University Press, vol. 2, 2003a, 493-512.

- "Domesticating the Exotic: Floral Culture and the East India Calico Trade with England, c. 1600-1800". Textile: The Journal of Cloth and Culture, vol. 1, no 1 (2003b), 65-85. DOI: http://dx.doi.org/10.2752/147597503778053135

- "Fashioning global trade: Indian textiles, gender meanings and European consumers, 1500-1800". How India clothed the world, The World of South Asian Textiles, 15001850, editado por Riello, Giorgio - Roy, Tirthankar. Leiden: Boston Brill, 2009, 365-390.

- Cotton (textiles that changed the world). Nueva York: Berg, 2011.

- "An Education in Comfort: Indian Textiles and the Refashioning of English Homes over the Long Eighteenth Century". En Selling Textiles in the long eighteenth century: comparative perspectives from Western Europe, editado por Stobart, Jon - Blondé, Bruno. Londres: Palgrave, 2014a, 13-29. DOI: http://dx.doi.org/10.1007/979-1-137-29521-7

- "Fashion Politics and Practice: Indian Cottons and Consumer Innovation in Tokugawa Japan and Early Modern England". En Dress and Ideology: Fashioning Identity from Antiquity to the Present, editado por Marzel, Shoshana-Rose - Stiebel, Guy D. London: Bloomsbury Academic, 2014b, 189-210. DOI: http://dx.doi.org/CBID181554

Lody, Raul Giovanni. "Pano da costa". Cadernos de Folclore, no 15 (1977).

López Beltrán, Carlos. "Sangre y temperamento. Pureza y mestizajes en las sociedades de castas americanas". En Saberes locales: ensayos sobre historia de la ciencia en América Latina, editado por Gorbach, Frida - López Beltrán, Carlos. Zamora: El Colegio de Michoacán, 2008, 289-342. 
Luque Agraz, Elin. Los relatos pintados, la otra historia. Exvotos mexicanos. Ciudad de México: Casa LAMM, 2010.

Machado, Pedro. "Cloths of a New Fashion: Indian Ocean Networks of Exchange and Cloth Zones of Contact in Africa and India in the Eighteenth and Nineteenth Centuries". En How India clothed the world, The World of South Asian Textiles, 1500-1850, editado por Riello, Giorgio - Roy, Tirthankar. Leiden: Boston Brill, 2009, 53-84.

Machuca, Paulina. "De porcelanas chinas y otros menesteres. Cultura material de origen asiático en Colima, siglos XVI-XVII". Relaciones. Estudios de Historia y Sociedad, $\mathrm{n}^{\circ}$ 131 (2012), 77-134.

Martínez Shaw, Carlos - Alfonso Mola, Marina. "The Philippine Islands: a vital crossroads during the first globalization period". Culture \& History Digital Journal, vol. 3, n 1 (2014), 1-16. DOI: http://dx.doi.org/10.3989/chdj.2014.004

Martins Torres, Andreia. "Quimonos chinos y quimones criollos. La moda novohispana en el cruce entre oriente y occidente". En La Nao de China, 1565-1815. Navegación, comercio e intercambios culturales, editado por Bernabéu, Salvador. Sevilla: Universidad de Sevilla, 2013, 247-279.

Matsunosuke, Nishiyama. Edo Culture. Daily Life and Diversions in Urban Japan, 16001868. Honolulu: University of Hawai'i Press, 1997.

Miño Grijalva, Manuel. Obrajes y tejedores de Nueva España, 1750-1810. Tesis Doctoral, Colegio de México, 1984.

- Obrajes y Tejedores de Nueva España. Madrid: ICI, 1990.

- La protoindustria colonial hispanoamericana. Ciudad de México: Fondo de Cultura Económica, 1993.

Morales Moreno, Humberto. "El carácter marginal y arrendatario del sistema de fábrica en paisajes agrarios mexicanos, 1780-1880". Anuario de Estudios Americanos. Sevilla, vol. 62, no 2 (2005), 163-185. DOI: http://dx.doi.org/10.3989/aeamer.2005.v62.i2.53

Ollé, Manel. La empresa de China. De la Armada Invencible al Galeón de Manila. Barcelona: El Acantilado, 2002.

Pacheco, José German. El añil: historia de un cultivo olvidado en Venezuela 1767-1870. Tesis Doctoral, Universidad Autónoma de Barcelona, 2000.

Parthasarathi, Prasannan. The Transition to a Colonial Economy: Weavers, Merchants and Kings in South India, 1720-1800. Cambridge: Cambridge University Press, 2001.

- "Cotton Textiles in the Indian Subcontinent, 1200-1800". En The spinning world: a global history of cotton textiles, 1200-1850, editado por Riello, Giorgio y Parthasarathi, Prasannan. Oxford. Oxford University Press, 2009, 17-41.

Pérez, Manuel. "Vicarious Consumers": Trans-national meetings between the West and East in the Mediterranean world (1730-1808). Londres: Ashgate, 2013.

Pérez Monroy, Atzin Julieta. La moda en la indumentaria: del Barroco a los inicios del Romanticismo en la ciudad de México (1785-1826). Tesis Doctoral, UNAM, 2001.

Phipps, Elena. "New Textiles in a New World: 18th Century Textile Samples from the Viceregal Americas". En Textile Society of America Symposium Proceedings. Nebraska: Textile Society of America, paper 898, 2014, 1-15.

Prakash, Om. The Dutch East India Company and the Economy of Bengal, 1630-1720. Princeton: Princeton University Press, 1985.

- "From Market-Determined to Coercion-Based Textile Manufacturing in EighteenthCentury Bengal". En How India clothed the world, The World of South Asian Textiles, 1500-1850, editado por Riello, Giorgio - Roy, Tirthankar. Leiden: Boston Brill, 2009, 217-251. 
Real Academia Española (RAE). “Zaraza”. En Diccionario de la lengua castellana compuesto por la Real Academia Española, reducido a un tomo para su más fácil uso. Quarta edición. Madrid: Viuda de Ibarra, 1780, 949.

- “Quimon". En Diccionario de la lengua castellana compuesto por la Real Academia Española, reducido a un tomo para su más fácil uso. Quarta edición. Madrid: Viuda de Ibarra, 1803, 708.

Riello, Giorgio. "East and West: Textiles and Fashion in Early Modern Europe". Journal of Social History, vol. 41, nº 4 (2008), 887-916. DOI: http://dx.doi.org/10.1353/jsh.0.0019

- "Asian Knowledge and the Development of Calico Printing in Europe in the Seventeenth and Eighteenth Centuries". Journal of Global History, vol. 5, no 1 (2010a), 1-28. DOI: http://dx.doi.org/10.1017/S1740022809990313

- "Fabricating the Domestic: The Material Culture of Textiles and Social Life of the Home in Early Modern Europe". En The Force of Fashion in Politics and Society: Global Perspectives from Early Modern to Modern Times, editado por Lemire, Beverly. Aldershot: Ashgate, 2010b, 41-65.

- Cotton: the fabric that made the modern world. Cambridge: Cambridge University Press, 2014.

- "Cotton: The making of a modern commodity". East Asian Journal of British History, vol. 5, no 1 (2016), 135-149.

Riello, Giorgio - Parthasarathi, Prasannan. "From India to the World: Cotton and Fashionability". En Handbook of the History of Consumption, editado por Trentmann, Frank. Handbook of the History of Consumption. Oxford: Oxford University Press, 2012, 145-170.

Riello, Giorgio - Parthasarathi, Prasannan (eds.). The spinning world: a global history of cotton textiles, 1200-1850. Oxford: Oxford University Press, 2009.

Riello, Giorgio - Roy, Tirthankar (eds.). How India clothed the world, The World of South Asian Textiles, 1500-1850. Leiden: Boston Brill, 2009.

Russel-Wood, A. J. R. Um mundo em movimento. Os portugueses na África, Ásia e América (1415-1808). Lisboa: Difel, 1991.

Sadao, Nishijima. "The formation of the early Chinese cotton industry". En State and Society in China: Japanese Perspectives on Ming-Quing Social and Economic History, editado por Grove, Linda - Daniels, Christian. Tokyo: University of Tokyo Press, 1984, 17-78.

Saito, Osamu. "Growth and Inequality in the Great and Little Divergence Debate: a Japanese Perspective". Economic History Review, vol. 68, nº 2 (2015), 399-419. DOI: http://dx.doi. org/10.1111/ehr.12071

Salvucci, Richard. Textiles y capitalismo en México. Una historia económica de los obrajes 1539-1840. México: Alianza, 1987.

Sanabrais, Sofía. "The Spaniards of Asia': The Japanese Presence in Colonial Mexico", Bulletin of Portuguese - Japanese Studies, vol. 18-19 (2009), 223-251.

Sánchez Silva, Carlos - Suárez Bosa, Miguel. "Evolución de la producción y el comercio mundial de la grana cochinilla, siglos XVI-XIX". Revista de Indias, vol. 56, n 237 (2006), 473-490. DOI: http://dx.doi.org/10.3989/revindias.2006.i237

Sanz, Eufemio Lorenzo. Comercio de España con América en la época de Felipe II. Valladolid: Servicio de Publicaciones de la Diputación Provincial de Valladolid, 1979.

Schwartz, Paul. Printing on Cotton at Ahmedabad, India in 1678. Ahmedabad: Calico Museum of Textiles, 1996.

Shimada, Ryuto. The Intra-Asian Trade in Japanese Copper by the Dutch East India Company during the Eighteenth Century. Leiden. Brill, 2006. 
Slack, Edward. "Orientalizing New Spain: Perspectives on Asian Influence in Colonial Mexico". Análisis, vol. 15, nº 43 (2012), 97-127.

Styles, John. "What were Cottons for in the Industrial Revolution?". En How India clothed the world, The World of South Asian Textiles, 1500-1850, editado por Riello, Giorgio Roy, Tirthankar. Leiden: Boston Brill, 2009, 207-326.

- “Indian Cottons and European Fashion, 1400-1800". En Global Design History, editado por Adamson, Glenn - Riello, Giorgio - Teasley, Sarah. Londres - Nueva York. Routledge, 2011, 37-46.

- "Fashion, Textiles and the Origins of Industrial Revolution". East Asian Journal of British History, $\mathrm{n}^{\circ} 5$ (2016), 161-189.

Subrahmanyam, Sanjay. "Rural industry and commercial agriculture in late seventeenth century south eastern India". Past \& Present, vol. 126, nº 1 (1990), 76-114. DOI: http:// dx.doi.org/10.1093/past/126.1.76

Subramanian, Lakshmi. "The Political Economy of Textiles in Western India: Weavers, Merchants and the transition to a Colonial Economy". En How India clothed the world, The World of South Asian Textiles, 1500-1850, editado por Riello, Giorgio - Roy, Tirthankar. Leiden: Boston Brill, 2009, 253-280.

Tanimoto, Masayuki. "A foreign fibre in early modern Japan”. En The spinning world: a global history of cotton textiles, 1200-1850, editado por Riello, Giorgio - Parthasarathi, Prasannan. Oxford: Oxford University Press, 2009, 194-201.

Thomson, Guy. Puebla de los Ángeles: industria y sociedad de una ciudad mexicana, 17001850. Puebla: BUAP, 2002.

Torres, Heloísa Alberto. "Alguns aspectos da indumentária crioula baiana". Cadernos Pagu, $\mathrm{n}^{\circ} 23$ (2004), 413-467.

Vicente, Marta. "Fashion, Race and Cotton Textiles in Colonial Spanish America". En The spinning world: a global history of cotton textiles, 1200-1850, editado por Riello, Giorgio - Parthasarathi, Prasannan. Oxford: Oxford University Press, 2009, 247-260.

Yuste, Carmen. Emporios Transpacificos. Comerciantes Mexicanos en Manila 1710-1815. México: UNAM, 2007. 